\title{
EDQM-HC Basic Dose Form Terminology
}

National Cancer Institute

\section{Source}

National Cancer Institute. EDQM-HC Basic Dose Form Terminology. NCI Thesaurus.

Code C150113.

Terminology subset about generalized versions of the pharmaceutical dose form, used to group together related pharmaceutical dose forms. 